\title{
Condition-dependent virulence of slow bee paralysis virus in Bombus terrestris: are the impacts of honeybee viruses in wild pollinators underestimated?
}

\author{
Robyn Manley ${ }^{1}$ (I) Mike Boots $^{1,2} \cdot$ Lena Wilfert $^{1}$
}

Received: 12 September 2016 / Accepted: 8 March 2017 / Published online: 30 March 2017

(C) The Author(s) 2017. This article is an open access publication

\begin{abstract}
Slow bee paralysis virus (SBPV) - previously considered an obligate honeybee disease-is now known to be prevalent in bumblebee species. SBPV is highly virulent in honeybees in association with Varroa mites, but has been considered relatively benign otherwise. However, condition-dependent pathogens can appear asymptomatic under good, resource abundant conditions, and negative impacts on host fitness may only become apparent when under stressful or resource-limited conditions. We tested whether SBPV expresses condition-dependent virulence in its bumblebee host, Bombus terrestris, by orally inoculating bees with SBPV and recording longevity under satiated
\end{abstract}

Communicated by Roland A. Brandl.

We show for the slow bee paralysis virus that virulence is condition dependent in a bumble bee host. This virus attacks also honey bees and therefore our results have consequences to evaluate the importance of pathogen pressure on wild bees. We hope that our result stimulates further studies on the impact of multi-host pathogens for the conservation of native pollinators.

Electronic supplementary material The online version of this article (doi:10.1007/s00442-017-3851-2) contains supplementary material, which is available to authorized users.

Robyn Manley

rm418@exeter.ac.uk

Mike Boots

mboots@berkeley.edu

Lena Wilfert

lena.wilfert@exeter.ac.uk

1 Centre for Ecology and Conservation, University of Exeter, Penryn Campus, Penryn TR10 9EF, UK

2 Department of Integrative Biology, University of California, Berkeley, 1005 Valley Life Sciences Building \#3140, Berkeley, CA 94720-3140, USA and starvation conditions. SBPV infection resulted in significant virulence under starvation conditions, with infected bees 1.6 times more likely to die at any given time point (a median of $2.3 \mathrm{~h}$ earlier than uninfected bees), whereas there was no effect under satiated conditions. This demonstrates clear condition-dependent virulence for SBPV in B. terrestris. Infections that appear asymptomatic in non-stressful laboratory assays may nevertheless have significant impacts under natural conditions in the wild. For multi-host pathogens such as SBPV, the use of sentinel host species in laboratory assays may further lead to the underestimation of pathogen impacts on other species in nature. In this case the impact of 'honeybee viruses' on wild pollinators may be underestimated, with detrimental effects on conservation and food security. Our results highlight the importance of multiple assays and multiple host species when testing for virulence, in order for laboratory studies to accurately inform conservation policy and mitigate disease impacts in wild pollinators.

Keywords Pollinators · Virulence $\cdot$ Virus $\cdot$ Bees .

Longevity

\section{Introduction}

Emerging infectious diseases are one of several key factors linked to pollinator decline (Manley et al. 2015; Vanbergen et al. 2013). Several fast-evolving Picorna-like RNA viruses, known to be pathogenic to honeybees (Carreck et al. 2010; Cox-Foster 2007; Genersch et al. 2010) have a broad host range, threatening ecologically and economically important wild pollinators (Manley et al. 2015; McMahon et al. 2015). Recent large-scale field studies have found deformed wing virus (DWV), black 
queen cell virus (BQCV), acute bee paralysis (ABPV) and slow bee paralysis virus (SBPV) to be prevalent in bumblebee species (Fürst et al. 2014; McMahon et al. 2015). High disease prevalence in wild, unmanaged pollinators-who play an important role as an ecosystem service (e.g. Garibaldi et al. 2013)—has raised concerns over the impact of diseases and the risk of spillover from managed honeybees (Fürst et al. 2014; Manley et al. 2015; Vanbergen et al. 2013). However, with the exception of DWV (Fürst et al. 2014), Israeli acute paralysis virus (IAPV) and Kashmir bee virus (KBV) (Meeus et al. 2014), the actual impact of viral diseases on wild pollinators is unknown.

Here, we used a controlled infection study to examine the impact of SBPV in a natural host, the bumblebee Bombus terrestris. SBPV is a picornavirus (de Miranda et al. 2010) which was first discovered in 1974 in an English honeybee (Apis mellifera) population. However, this virus is common in a range of bumblebee species and at its highest prevalence in $B$. hortorum in the UK (McMahon et al. 2015). In A. mellifera, SBPV only causes high mortality in association with the recently emerged ectoparasitic mite Varroa destructor, while otherwise appearing asymptomatic (Carreck et al. 2010; SantillánGalicia et al. 2014). SBPV causes paralysis in the two anterior pairs of legs 10 days after injection into the haemolymph (Bailey and Woods 1974). Varroa, which exclusively infests honeybees, feeds on hemolymph and can thus serve as a vector directly transmitting viral infections into the hemolymph. Field studies that have found virus-positive pollinator species have collected foraging individuals (Evison et al. 2012; Levitt et al. 2013; Singh et al. 2010). Recent UK-wide data finds on average $5 \%$ of apparently healthy foraging bumblebees harbouring SBPV, with more than a third of SBPV-positive individuals carrying high viral titres $\left(>10^{9}\right.$ virus particles per individual) (McMahon et al. 2015). Based on these field-surveys, it is clear that SBPV is found in nature but seems to exist asymptomatically.

Virulence in its broad sense is a measure of pathogen impact on host fitness. While some pathogens are highly virulent, imposing fitness costs on hosts that lead to mortality and reduced fecundity, others often seem to have no obvious impact. However, in seemingly benign pathogens, costs may be hidden if the host is able to compensate for the impacts through increased resource use, but revealed under starvation conditions when resources are too low to maintain defence costs (Moret and SchmidHempel 2000). Increased virulence under environmental stress is a common phenomenon across a range of pathogens and their hosts (Boots and Begon 1994; Jaenike et al. 1995; Jokela et al. 2005; Koella and Offenberg 1999; Restif and Kaltz 2006; Steinhaus 1958) and has been documented in honeybees and bumblebees (Brown et al. 2000; Goulson et al. 2015; Moret and SchmidHempel 2000). It is therefore important to examine the impact of pathogens across a range of host resource conditions.

Condition-dependent virulence has the potential to impact on individual bees, colonies and populations of wild pollinators, potentially contributing to population declines under poor environmental conditions. The availability of multiple reservoir species may also affect a pathogen's virulence and mask the fitness effects of pathogen infection in wild hosts (Leggett et al. 2013). Moreover, in a multihost-pathogen system there is potential to underestimate the impact of pathogens, as sentinel species used in lab studies may not be representative if they are assayed under conditions of resource superabundance. For example, $A$. mellifera, the sentinel species in many pesticide studies, are less susceptible to dietary imidacloprid, a systemic neonicotinoid, than $B$. terrestris; therefore raising concern about the true impact of this pesticide on wild pollinator populations (Cresswell et al. 2012). In a survey of honeybees and five bumblebee species in the UK, the mean prevalence of SBPV in $B$. terrestris was comparable to honeybees and other bumblebee species at $\sim 6 \%$, while $B$. hortorum had a significantly higher prevalence (McMahon et al. 2015), thus differences in host susceptibility and potentially host tolerances may exist. An understanding of the condition dependence of virulence, the impact on non-apis hosts, and the likely environmental changes that populations are experiencing is therefore critical to an assessment of the impact of these pathogens on wild pollinator communities.

\section{Materials and methods}

We used three B. terrestris colonies (Biobest Belgium N.V.) in the experiments and kept them at $28{ }^{\circ} \mathrm{C}$ with ad libitum irradiated pollen (Biobest, gamma radiation) and sugar water. We used Invertbee feed sugar (BelgoSuc), which has a sugar content of $71.4 \%$, and was diluted $1: 1$ with water. We confirmed the absence of four common bee viruses (deformed wing virus (DWV), black queen cell virus (BQCV), SBPV and acute bee paralysis virus (ABPV) (McMahon et al. 2015) by RT-PCR (see methods below and supplementary tables S1 and S2 for details) in ten bees from each colony ( $>20 \%$ of the young colony). Graystock et al. (2013) found that in colonies where DWV was present, $>10 \%$ of bees within the colony were infected with the virus. Thus, screening $>20 \%$ of the colony is sufficient to determine virus-free status. Phase-contrast microscopy of faeces and gut tissue samples from the same ten bees per colony confirmed the absence of the gut parasites Nosema spp, Crithidia spp and Apicystis bombi. Bees were handled 
throughout the experiment using forceps that were flamed between individuals.

To imitate a naturally occurring infection, we prepared virus inoculum from five naturally SBPV-infected wildcaught bees from Scotland $(2 \times B$. hortorum and $3 \times B$. pascuorum), known to be uninfected by DWV, BQCV and ABPV by previous PCR. We homogenised their abdomen in $400 \mu \mathrm{l}$ of insect ringer solution per bee and combined them into one inoculum solution. We prepared the control inoculum in the same way from uninfected colony bees. SBPV and control inocula were confirmed by RT-PCR to be SBPV positive and negative, respectively.

\section{Experimental set-up}

\section{Infection time course}

To determine the pattern of SBPV infection in the bee guts over time, we collected 50 bees from each of the three colonies of random age and size. We confined all bees individually in tubes and starved them for $2 \mathrm{~h}$ before dosing them with $10 \mu \mathrm{l}$ of sugar water solution, containing $5 \mu \mathrm{l}$ of SBPV extract. The $10 \mu \mathrm{l}$ droplet was pipetted onto the upper side of the tube and all bees were observed to drink the droplet until no liquid was visible. We then maintained bees individually with ad libitum pollen and sugar water. We killed three bees per colony every 2 days for 14 days, then once a week until day 28. Guts were dissected from each bee for qPCR analysis (see below). Full guts were used in this assay to track viral loads in the gut specifically, as faecaloral transmission is thought to be a primary transmission route for insect viruses. Dose was determined from analysis of day zero bees (killed $2 \mathrm{~h}$ post dosing) to be directly comparable to the other time points.

\section{Longevity under satiated conditions}

We collected 142 newly emerged worker bees over 4 days from the same three colonies (46, 59 and 37, respectively, from colonies A, B and C). It was essential to use sameage bees when comparing time to death between treatment groups under satiated conditions because of the bees's long lifespan (up to 3 months). Gut fauna was reconstituted by feeding all bees a $10 \mu \mathrm{l}$ preparation of faeces mixed with sugar water, which we collected from worker bees in the corresponding colony (Koch and Schmid-Hempel 2011). At 6 days old, we dosed and maintained the bees as detailed above. The experiment continued for 95 days, by which point $94 \%$ of bees had died; we killed the eight surviving bees. We collected dead bees daily and stored them at $-80{ }^{\circ} \mathrm{C}$.

\section{Longevity under starvation conditions}

It is paramount to use bees from the same colonies in each assay, as colony-specific gut microbiota play a role in immunity (Koch and Schmid-Hempel 2012). Thus, to reach a sufficient sample size we collected 150 worker bees (age range 0-3 week-old) from the same three colonies (50 per colony); bees were randomly allocated to either the treatment or the control group, each individually fed with $10 \mu \mathrm{l}$ of sugar water solution, containing either $5 \mu$ of SBPV extract or control extract, respectively. To control for age and allow for the acquisition of the normal gut flora, all workers in the colonies were marked on a set day and experimental bees were then randomly chosen and allocated from unmarked bees that had emerged over a 3-week period to randomise age differences across treatments. We maintained workers individually with ad libitum pollen and sugar water. On day 10 post-infection, we starved all surviving individuals $(N=144)$ of pollen and sugar water and recorded time to death every $15 \mathrm{~min}$ until $56 \mathrm{~h}$, at which point we killed the six surviving individuals. Death was confirmed by lack of movement when we turned the tubes at each 15 min time point.

\section{RNA extractions and RT-PCR}

To allow for multiple assays, we cut all bees from the two longevity assays in half laterally. Guts were extracted from infection time course bees. One half bee, or gut extract, was used to determine infection status through RT-PCR. We extracted RNA individually from each sample using Trizol@ (Invitrogen, Carlsbad, CA, USA) following the manufacturer's instructions. Briefly, samples were homogenised with glass beads in $1.3 \mathrm{ml}$ Trizol@ in a tissue-lyser (note; $500 \mu \mathrm{l}$ of Trizol was used for the guts). RNA was separated using bromo-chloropropane and precipitated in isopropanol. The RNA was washed with $75 \%$ ethanol and re-suspended in $400 \mu$ lof diethylpyrocarbonate (DEPC)treated water. We converted $2 \mu$ l of RNA into first-strand cDNA using GoScript ${ }^{\mathrm{TM}}$ Reverse Transcriptase, according to the manufacturer's instructions (Promega) using random hexamer primers and $\mathrm{RNasin}^{\circledR}$ to avoid RNA degradation. SBPV positive RNA and water negatives were run as controls.

SBPV specific forward (5'-GAGATGGATMGRCCTGAAGG- $3^{\prime}$ ) and reverse primers (5'-CATGAGCCCAKGARTGTGAA- $3^{\prime}$ ) were used to amplify a 915 bp cDNA fragment by PCR. We designed primers based on the published Rothamsted strain coding region [EU035616 (de Miranda et al. 2010)]. We carried out PCR in $20 \mu \mathrm{l}$ reactions using GoTaq ${ }^{\circledR}$ DNA Polymerase, with 35 amplification cycles, an annealing temperature of $55^{\circ} \mathrm{C}$ for 30 and $20 \mathrm{~s}$ of extension at $72{ }^{\circ} \mathrm{C}$ (table S1). Every run included 
a known positive SBPV sample and a water negative as controls. $5 \mu$ of PCR product were run on $1.5 \%$ TAE agarose gel and RedSafe ${ }^{\mathrm{TM}}$ nucleic acid staining solution. In addition, we carried out PCR with arginine kinase (AK), a stable reference gene for $B$. terrestris (Horňáková et al. 2010 ), to check the quality of RNA extractions (primers: 5'-TGACAAGCATCCACCAAAAG-3', 5'-TCGTCGATCAGTTTCTGCTG-3'), amplifying a 263 bp fragment using the PCR programme as above.

\section{Real-time quantitative RT-PCR}

RNA extractions from all bee guts in the infection time course were measured on a Nanodrop 1000 spectrometer. 260/280 ratios ranged from 1.81 to 2.03 with $64 \%$ of samples falling between 1.9 and 2.03. Two samples fell below 1.8 and were excluded from qPCR analysis. All remaining samples were run on a Qubit ${ }^{\circledR}$ 3.0 Fluorometer using the Qubit ${ }^{\circledR}$ RNA quantification assay: RNA concentrations ranged from 1.8 to $207 \mathrm{ng} / \mu \mathrm{l}$. This range was accounted for by diluting all sample RNA to $5 \mathrm{ng} /$ $\mu \mathrm{l}$ (using RNase/DNase free water). Samples that were already at $5 \mathrm{ng} / \mu \mathrm{l}$ or below $(N=10)$ were used directly.

One-step absolute quantification of SBPV was carried out on the Step One ABI Applied Biosystems qPCR machine. Taqman ${ }^{\circledR}$ primer and probe assays were designed and optimised by Primerdesign $\odot$ for SBPV and an endogenous control bee gene, Actin beta (ACTB) (SBPV; Accession Number EU035616, context sequence length -138 and the anchor nucleotide-4189: and ACTB; Accession Number FN391379, context sequence length-211 bases and the anchor nucleotide-641).

Each sample was run in duplicate for both SBPV and ACTB assays on each plate, along with a no-template control, and a five point standard curve (1:10 dilution series) also run in duplicate. Reactions were carried out with Precision one-step mastermix and $2.5 \mu 1$ of RNA in $12.5 \mu \mathrm{l}$ reactions, according to the manufacturer's instructions. Reverse transcription occurred at $42{ }^{\circ} \mathrm{C}$ for $10 \mathrm{~min}$, enzyme activation took place at $95^{\circ} \mathrm{C}$ for $8 \mathrm{~min}$, followed by 40 cycles of amplification at $95{ }^{\circ} \mathrm{C}$ for $10 \mathrm{~s}$ and data collection at $60{ }^{\circ} \mathrm{C}$ for $1 \mathrm{~min}$. The standard curve was created using a SBPV positive control provided by Primerdesign with a known quantity of $2 \times 10^{5}$ viral particles per $\mu \mathrm{l}$, thus SBPV could be quantified between $5 \times 10^{1}$ and $5 \times 10^{5}$ viral copies (figure S1). SBPV assay efficiency ranged from 90.3 to $92.4 \%$ across plates. Quantitation cycle $(\mathrm{Cq})$ values and absolute viral quantities were calculated using StepOne software. ACTB $\mathrm{Cq}$ values were in the range of 17.4-24.8 Cq and stayed stable relative to SBPV Cq values (figure S2), confirming extraction of a valid biological template.

\section{Body size and fat content}

For both longevity assays, we measured the length of the radial wing cell, using a Leica camera microscope and ImageJ, as a proxy for body size (Brown et al. 2000). For the starvation assay, we used the second half of each individual to measure fat content - as a proxy for condition — by adapting methods from Ellers (1996): the half abdomen were dried at $70{ }^{\circ} \mathrm{C}$ for 3 days and then weighed with a precision balance, before being placed in $2 \mathrm{ml}$ of dichloromethane:methanol (2:1 mix) for 2 days, dried at $70{ }^{\circ} \mathrm{C}$ for another 3 days and weighed again. The difference between the two weights is taken as a proxy for the amount of fat. The relative fat content is the ratio of amount of fat $(\mathrm{mg})$ and radial wing cell length $(\mathrm{mm})$.

\section{Statistical analysis}

We carried out all analyses in R v3.2.3. We used the lme4 package (Bates et al. 2015) to run a GLMM (generalised linear mixed model) modelling log viral load as dependent on time post-infection and host colony, with qPCR plate $(N=7)$ as a random effect. Lmertest was used to determine significance. Model simplification, using term removal and Anova for model comparison, was used to determine the minimum adequate model of best fit. After model simplification, goodness of fit was determined using residual plots. One-sided Kolmogorov-Smirnov tests were used to determine significant differences in viral load between time points.

For survival analysis we used the Survival package (Therneau 2008). Possible confounding correlations between body size and relative fat content were tested and found to be insignificant. Kaplan-Meier survival curves were produced using the survfit function; the survdiff function was used to test the difference between curves with a log-rank test. We used the coxph function to determine the effects of infection status, body size and relative fat content on the survival of bees, with the frailty function used to fit colony as a random term in the survival models. We checked for correlations between fixed factors using the cor.test function. Model simplification, using term removal and Anova for model comparison, was used to determine the minimum adequate model of best fit. We checked models for the assumption of proportionality of hazards using the cox.zph function.

\section{Results}

\section{SBPV infection course}

To confirm that SBPV replicates in bumblebees, we tracked SBPV in inoculated bees for 28 days (Fig. 1). Day post-inoculation is a significant factor determining 
log viral load (GLMM: $t=-3.8_{59.4}, p<0.001$ ). Bees killed on day zero, $2 \mathrm{~h}$ post-inoculation, had a mean viral load of $1.5 \times 10^{4}$ copies per ng of RNA (ranging from $8 \times 10^{3}$ to $2.5 \times 10^{4}$ copies, $N=9$ ), corresponding to a mean of $3 \times 10^{7}$ copies per bee gut. There was a reduction in mean viral load between day zero and day two to less than 50 copies per ng of RNA (ranging from viral absence to 103 copies, $N=8$ ). Compared to day two, viral loads were significantly higher on day four [mean $=3.4 \times 10^{5}$ viral copies $(N=9), D=0.9, p<0.01]$, day six $\left[\right.$ mean $=10 \times 10^{5}$ viral copies $(N=9), D=0.9$, $p<0.01$ ], day eight [mean $=1.6 \times 10^{3}$ viral copies $(N=9), D=0.7, p=0.01]$, day ten [mean $=1.4 \times 10^{2}$ viral copies $(N=7), D=0.7, p=0.02]$ and day fourteen $\left[\right.$ mean $=3.8 \times 10^{2}$ viral copies $(N=4), D=1$, $p=0.006$ ] (Fig. 1), implying that the virus results in a replicating infection. Two bees out of 64, both from colony A, replicated the virus beyond the initial viral load, reaching viral loads of $3 \times 10^{6}$ and $9.7 \times 10^{6}$ per ng of RNA, on day four and six, respectively).

\section{Survival assays}

There is a significant difference in survival between SBPV-positive and SBPV-negative bees when stressed by starvation (Fig. $2 ; N=119$, log-rank test: $\chi^{2}=4.5_{1}$, $p=0.03$ ) with a median difference in survival of $2.3 \mathrm{~h}$, but no difference under satiated conditions (Fig. 3;
$N=121$, log-rank test: $\left.\chi^{2}=2.3_{1}, p=0.1\right)$. Longevity did not vary according to host colony in our experiment (log-rank test for starvation: $\chi^{2}=4.2_{2}, p=0.1$, and satiated conditions: $\chi^{2}=2.2_{2}, p=0.3$ ).

\section{SBPV infection status}

SBPV inoculated bees are able to clear infection: with 34 of 77 starvation bees clearing infection before being killed at day 10 post-inoculation, and 14 of 73 satiated

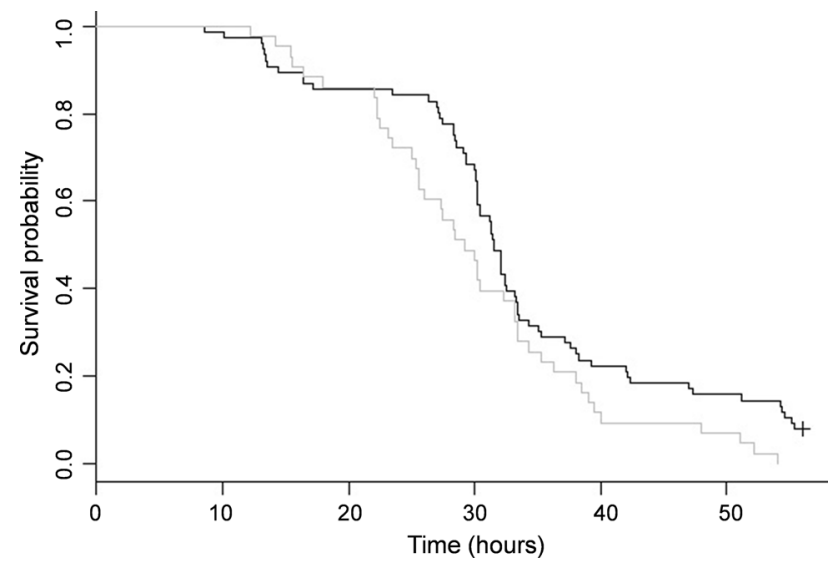

Fig. 2 Kaplan-Meier survival curves for bees infected with slow bee paralysis virus (SBPV) (grey) and disease-free bees (black) during the starvation assay (contaminated controls excluded)

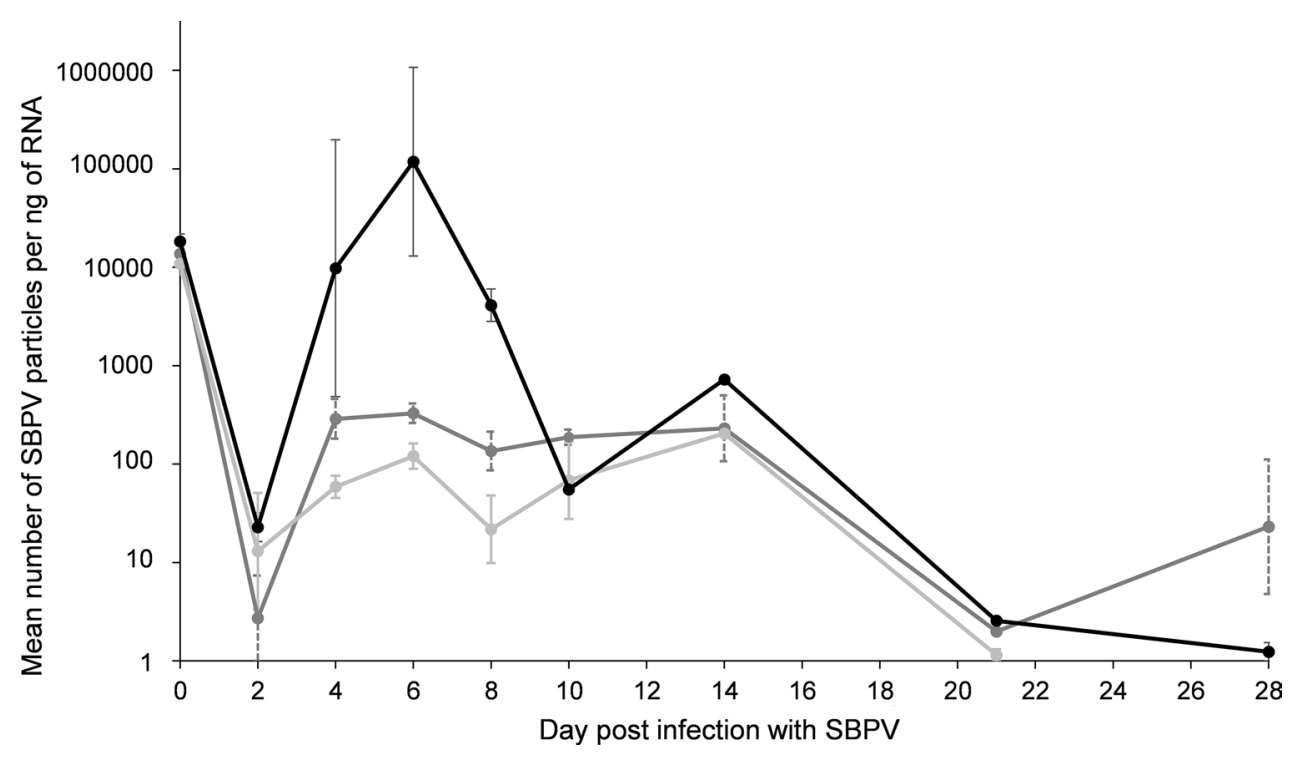

Fig. 1 Mean slow bee paralysis virus (SBPV) load (viral copies per ng of RNA) per colony over a 28-day time course of SBPV infection in the guts of $B$. terrestris. Three guts per colony were analysed per time point on day $0,2,4,6,8,10,14,21$, and 28 (note; only 1 or 2 samples were analysed per colony at days 14 and 21, and no bees remained on day 28 to kill for colony C). Standard error bars are included (note; not for days 14 and 21 when there were less than two data points. Key: colony A (black), colony B (dark grey) and colony $\mathrm{C}$ (light grey). Asterisk above a time point indicates a significant increase in viral load compared to day two, across all colonies (onesided Kolmogorov-Smirnov tests). Note log scale used on $\mathrm{Y}$ axis 


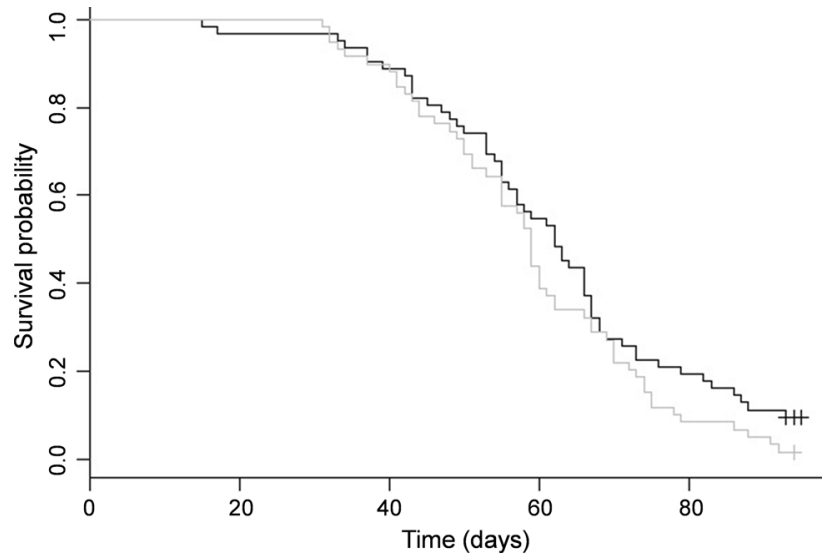

Fig. 3 Kaplan-Meier survival curves for bees infected with slow bee paralysis virus (SBPV) (grey) and disease-free bees (black) during the satiated assay (contaminated controls excluded)

bees clearing infection before they died naturally at various ages. Interestingly, there is a significant difference in virus clearance rates between the two assays (test of proportions; $\left.\chi^{2}=9.6_{1}, p<0.01\right)$. SBPV appears to be highly contagious by a transmission route other than direct inoculation. Even though the experimental set-up prevented any direct contact between control bees and SBPV, 26 of 68 starvation control bees and 21 of 69 satiated control bees became contaminated with SBPV during the experiment. Note, there is no significant difference in number of contaminated controls between assays (test of proportions; $\chi^{2}=0.4_{1}, p=0.5$ ). Thus, for the analysis we compared infected versus uninfected bees, rather than inoculated versus control bees (table S3). Based on qualitative electrophoresis gel data, it is notable that inoculated bees have a range of viral loads, while contaminated control bees generally have a low viral load (figure S3).

It is important to note that the route of infectionwhether inoculation or contamination-does not affect the overall results. Bees positive for SBPV had reduced longevity under starvation conditions when all bees are included in the analysis [median difference in survival $=1.34 \mathrm{~h} ; N=145, \mathrm{HR}=1.4(1.0-2.0), \chi^{2}=3.8_{1}$, $p=0.05]$, if all control bees are removed from analysis [median difference in survival $=3 \mathrm{~h}$; Cox regression: $N=77, \mathrm{HR}=1.87$ (1.1-3.16), $\left.\chi^{2}=5.42_{1}, p=0.02\right]$, or if only infected controls are removed (median difference in survival $=2.3 \mathrm{~h}$ (Table 1) (table S3). Although interesting, we do not know enough about the route of infection or the dose of SBPV received by contaminated controls to draw any conclusions, and have thus excluded them from the main survival analysis for both starvation and satiated conditions.
Starvation conditions

Of the 119 workers in the starvation assay (excluding the infected controls), 113 subsequently died during the experiment. A maximal Cox proportional hazards regression model included the effects of infection status, body size, relative fat content and host colony, as well as an interaction between infection status and fat content, on the survival of bees. Infection status was significant (hazard ratio $(\mathrm{HR})=1.6,95 \%$ CIs $\left.[1.0,2.3], \chi^{2}=4.5_{1}, p=0.03\right)$. Based on the hazard ratio, SBPV-infected bees are 1.6 times more likely to die at a given time point compared to uninfected bees. The data also suggests that the risk of death decreases with increasing relative fat content $(\mathrm{HR}=0.4,95 \% \mathrm{CIs}$ $\left.[0.2,1.0], \chi^{2}=3.3_{1}, p=0.07\right)$. Host colony was fitted as a random effect, and although not significant, it was retained as an important variable within the model. There was no interaction between fat content and body size with infection status. All variables satisfied the assumption of proportional hazards (table S4a). The overall model was significant (likelihood ratio test: $13.9_{3.94}, p=0.007$ ) (Table 1).

As a result of the ability of inoculated bees to clear infection, the data can be divided into three groups: (1) SBPV-positive bees that were inoculated and maintained infection $(N=43)$, (2) SBPV-negative bees that were inoculated but cleared infection $(N=34)$, and (3) SBPVnegative control bees $(N=42)$. Note, we assume $100 \%$ of inoculated bees initially became infected based on qPCR data from our infection time course (Fig. 1). Interestingly, bees that cleared infection did not differ in survival from control bees; but both these SBPV-negative groups differ in survival from SBPV-positive inoculated bees (Table 2 and figure S4: note, these also includes pairwise comparison with contaminated controls, indicating that survival of SBPV-positive contaminated control bees does not significantly differ from survival of SBPV-positive inoculated bees).

\section{Satiated conditions}

Of the 121 workers in the satiated assay (excluding the infected controls), 114 subsequently died during the experiment. Infection had no significant effect on survival but was retained in the model as an important variable. Batch had no effect on survival and was removed from the model by model simplification. Only body size had a positive significant effect on survival (HR $=0.4$ CIs [0.2, 0.8], $\left.\chi^{2}=6.49_{1}, p=0.01\right)$ (Table 1$)$. Host colony was not significant but was retained as an important variable within the model. The overall model was significant (likelihood ratio test: $10.3_{3.94}, p<0.03$ ). All variables satisfied the assumption of proportional hazards (table S4b). Under satiated 
Table 1 Cox regression models comparing survival of slow bee paralysis virus (SBPV)-infected bees to SBPV-free bees under starvation conditions and favourable conditions. Colony was fitted as a random effect

\begin{tabular}{|c|c|c|c|c|c|c|}
\hline \multirow{2}{*}{$\begin{array}{l}\text { Variable } \\
\text { Starvation conditions }(N=119, \\
\text { events }=113)\end{array}$} & \multirow[t]{2}{*}{ Regression coefficient (b) } & \multirow[t]{2}{*}{ SE (b) } & \multirow[t]{2}{*}{$p$ value } & \multirow[t]{2}{*}{$\operatorname{HR}\left(\mathrm{e}^{\mathrm{b}}\right)$} & \multicolumn{2}{|c|}{$95 \%$ CIs for HR } \\
\hline & & & & & Lower & Upper \\
\hline $\begin{array}{l}\text { Infection status }(0=\text { not infected, } \\
1=\text { infected })\end{array}$ & 0.4 & 0.2 & $0.03 * *$ & 1.6 & 1.0 & 2.4 \\
\hline Colony A & & & & 0.8 & 0.2 & 2.6 \\
\hline Colony B & $\mathrm{n} / \mathrm{a}$ & $\mathrm{n} / \mathrm{a}$ & 0.12 & 0.9 & 0.3 & 3.0 \\
\hline Colony $\mathrm{C}$ & & & & 1.3 & 0.4 & 3.0 \\
\hline Fat ratio & -0.8 & 0.5 & $0.07 *$ & 0.4 & 0.2 & 1.0 \\
\hline Body size (wing) & 0.3 & 0.4 & 0.4 & 1.4 & 0.6 & 3.4 \\
\hline Overall model & Likelihood ratio $=13.9_{3.94}$ & & & $p=0.007^{* *}$ & & \\
\hline \multicolumn{7}{|l|}{$\begin{array}{l}\text { Favourable conditions }(N=121, \\
\quad \text { events }=114)\end{array}$} \\
\hline Body size (wing) & -1.0 & 0.4 & $0.01 * *$ & 0.4 & 0.2 & 0.8 \\
\hline $\begin{array}{l}\text { Infection status }(0=\text { not infected, } \\
1=\text { infected })\end{array}$ & 0.2 & 0.2 & 0.2 & 1.3 & 0.9 & 1.9 \\
\hline Batch number $(1,2,3,4)$ & 0.1 & 0.1 & 0.2 & 1.2 & 1.0 & 1.4 \\
\hline Colony A & $\mathrm{n} / \mathrm{a}$ & $\mathrm{n} / \mathrm{a}$ & 0.3 & 1.2 & 0.4 & 3.8 \\
\hline Colony B & & & & 1.0 & 0.3 & 3.2 \\
\hline Colony $\mathrm{C}$ & & & & 0.8 & 0.2 & 2.7 \\
\hline Overall model & Likelihood ratio $=10.3_{3.94}$ & & & $p=0.03 * *$ & & \\
\hline
\end{tabular}

$H R$ hazard ratio, CIS 95\% confidence intervals for HR. Variables underlined are included in the final model, variables that are not underlined were included in maximal models but removed by model simplification

** Indicates significance at $95 \%$ and *at $90 \%$. Overall model fit refers to the minimum adequate model

Table 2 Kaplan-Meier logrank test results between the survival probabilities of four groups of bees under starvation conditions: inoculated $(+)$ are SBPV inoculated bees that maintained infection, inoculated $(-)$ are inoculated bees that cleared infection, controls $(+)$ are control bees that became infected indirectly, and controls $(-)$ are control bees that remained clean

\begin{tabular}{llll}
\hline & Inoculated $(+)$ & Inoculated $(-)$ & Controls $(+)$ \\
\hline Inoculated $(+)(n=43)$ & & & \\
Inoculated $(-)(n=34)$ & $\chi^{2}=4_{1}, p=0.045 * *$ & & \\
Controls $(+)(n=26)$ & $\chi^{2}=0.4_{1}, p=0.506$ & $\chi^{2}=1.3_{1}, p=0.2$ & \\
Controls $(-)(n=42)$ & $\chi^{2}=3.7_{1}, p=0.077 *$ & $\chi^{2}=0.1_{1}, p=0.7$ & $\chi^{2}=0.7_{1}, p=0.415$ \\
\hline
\end{tabular}

The number of bees in each group is recorded in parentheses

** Indicates significant difference in survival between two groups at $95 \%$ and * at $90 \%$ conditions there was no difference in survival between the four groups mentioned above [(1) SBPV-positive bees that were inoculated and maintained infection $(N=59)$, (2) SBPV-negative bees that were inoculated but cleared infection $(N=14)$, (3) SBPV-negative control bees $(N=48)$ ] and (4) SBPV-positive contaminated control bees $(N=21)$ $\left(\chi^{2}=2.4_{3}, p=0.5\right)$.

\section{Colony effects}

There are colony differences in susceptibility to SBPV, with colony A showing significantly higher titres compared to the other two colonies (Fig. 1, GLMM; $t=5.3_{5.8}, p<0.001$ ). In addition, colony A was significantly less able to clear infection in the starvation assay $\left(\chi^{2}=12.1, p=0.002\right)$ : poststarvation (i.e. day 10 post-infection) $44 \%(N=77)$ of inoculated bees were clear of infection-in colony A only $19 \%$ (5 of 26) of inoculated bees had cleared infection by day 10 , while $60 \%$ ( 15 of 25 ) and $58 \%$ (15 of 26) of individuals had cleared the infection in colony B and C, respectively. In the longevity assay, few bees had cleared infection at the time of death $[12.5 \%(n=24), 27 \%(n=30)$ and $15.8 \%$ $(n=19)$ in colony A, B and C, respectively, with no significant differences between colonies $\left(\chi^{2}=1.9, p=0.38\right)$. 


\section{Discussion}

Slow bee paralysis virus is widespread and prevalent across bumblebee species in the UK and occurs in apparently healthy foraging individuals (McMahon et al. 2015). Our results demonstrate that SBPV has the potential to exert a hidden cost on its host $B$. terrestris. Under satiated conditions, when $B$. terrestris have unlimited access to food, SBPV infection has no effect on longevity; while, under starvation conditions, the longevity of infected bees is significantly reduced-they are 1.6 times more likely to die at each time point. Under lab conditions, infected bees survived on average $2.3 \mathrm{~h}$ less under starvation. In the wild, periods of starvation are likely to occur frequently for bumblebees due to adverse weather conditions such as high winds, rain or cold weather. Unlike honeybees, bumblebees do not have significant honey stores in their nests. A decreased survival of a median of $2.3 \mathrm{~h}$ would thus be ecological significant for bumblebees in the wild (Brown et al. 2000); more importantly, this effect would most likely be exacerbated under real life conditions where individuals need to expend additional energy for, e.g. thermoregulation and flight, therefore the impact of viral infection may be underestimated here.

The experimental starvation conditions used in this experiment were designed to imitate natural situations where poor weather can prevent bees foraging for extended periods. Both pollen and nectar are critical energy resources for bumblebees, and colonies suffering from an energy shortfall are less effective at protecting the colony from predators, social parasites (Cartar and Dill 1991) and pathogens (Alaux et al. 2010; Moret and Schmid-Hempel 2000). As our results show, the virulence of a viral pathogen, which may appear asymptomatic under benign conditions, is also unmasked under such energy-limited conditions. Given such synergistic effects of environmental stress and disease there is clearly the need for more consideration of spillover effects of viral disease between managed bees and wild pollinators.

Condition-dependent virulence has been demonstrated in bumblebees for the gut parasite Crithidia bombi, which also decreases survival under starvation (Brown et al. 2000). C. bombi additionally exerts fitness costs during stressful times in the bumblebee life cycle, such as queen hibernation and colony foundation (Brown et al. 2003). For bee viruses, condition-dependent virulence of DWV has been demonstrated under pesticide stress (Di Prisco et al. 2013) as well as nutritional stress (DegrandiHoffman et al. 2010). In some sense, co-infection of viruses with the ectoparasitic honeybee mite $V$. destructor is probably the best documented example of conditiondependent virulence [SBPV (Carreck et al. 2010), DWV
(Martin et al. 2012), ABPV (Genersch et al. 2010) and IAPV (Di Prisco et al. 2011)]. However, the mechanisms of increased virulence in this case are more complicated. Although $V$. destructor weakens the bees and may cause immunosuppression (Nazzi et al. 2012; Yang and CoxFoster 2005) similar to other environmental stresses, the mite itself increases viral virulence in its capacity as a virus vector (Martin 2001).

It is probable that, like C. bombi, other conditiondependent pathogens of bumblebees such as SBPV will affect colony fitness beyond mere survival to starvation. Clearly these individual and colony effects can lead to population level responses and pathogens are well documented to exert large effects on their host's ecology (e.g. Anderson and May 1981; Hatcher et al. 2006). Theoretical models and eventually species specific simulation models would be useful in determining the likely population level effects of the individual impact of condition-dependent virulence under variable resource conditions.

The precise mechanism by which SBPV reduces host longevity under starvation conditions is unclear. It is possible that infection induces a costly response by the host immune system; in this scenario, the host is unable to maintain a defence against the virus when resources are withheld, resulting in increased virus virulence and reduced lifespan (Moret and Schmid-Hempel 2000). It is also possible that infection reduces the resources in the gut that are available to the bee, or inhibits uptake of resources, as may be the case for trypanosomal gut parasites (Gorbunov 1987, 1996; Jensen et al. 1990). Such effects may be exacerbated by any damage caused by viral replication within its host, with the pathogen's virulence likely to be determined by a combination of these factors.

Bees with higher body fat have reduced risk of death under starvation conditions, while body size itself has no effect. The fat body is key for immunity and longevity; it is the main site of energy and protein storage, synthesis of immunoproteins, and vitellogenin synthesis involved in longevity (Amdam and Omholt 2002). In B. terrestris workers, fat body increases with age (Moret and SchmidHempel 2009). As the bees in this assay were of mixed age (within 3 weeks of each other), although randomised across treatments, it is possible the relationship between fat body and survival could be linked to age. Body size had no effect on longevity over short-term starvation but had a significant positive effect on longevity under satiated conditions. Body size is determined by conditions during larval development. Maintaining brood at $30{ }^{\circ} \mathrm{C}$ requires high energy consumption (Heinrich 1974). When resources are low, workers cease incubating and the brood temperature drop, which slows the development and potentially causes developmental defects (Barrow and Pickard 1985). Low body size and body fat are both symptoms of a lack of resources 
and reduce individual longevity, which could have consequences at a colony and population level.

Many measured immune defences decrease with age in B. terrestris workers, i.e. antibacterial activity, encapsulation and melanisation, haemocyte concentration and phenoloxidase activity, with declines seen within a biologically relevant age range (Doums et al. 2002; Moret and Schmid-Hempel 2009). It is interesting that the ability of bees in the starvation assay to clear viral infection is significantly higher than for bees in the satiated assay. Because of the mixed age of starvation bees it is important to consider how immunosenescence could influence viral clearance rates. The starvation bees were older (on average) at the time point of inoculation because of the age range 0-3 weeks (1-21 days old), while satiated bees were all inoculated at 6 days old. Thus, a higher viral clearance rate in older bees is contrary to the immunosenescence reported for the aspects of humoral and cellular immune defences in B. terrestris, mentioned above. However, not all immune measures decrease with age, e.g. fat body (Moret and Schmid-Hempel 2009). It is conceivable that anti-viral defences against oral-faecal infections might be stronger in older bees. In addition, in contrast to individual age, some immune measures increase with colony age. Moret and Schmid-Hempel (2009) found that B. terrestris workers born when the colony is young have lower concentration of haemocytes and lower PO activity than those born later in the colony life cycle. As starvation bees emerged at a later point in each colony's life cycle, compared to satiated bees, increased immunity with colony age could also explain why starvation bees cleared infection at significantly higher rates. It is clear that experiments dedicated to studying immunosenescence of anti-viral defences in social insects are needed to understand the impact of viral infections on wild populations.

The dose of SBPV used in this study came from a natural infection and is high enough to cause an initial infection in the majority of inoculated bees, with condition-dependent effects on longevity. The infection persisted up to 95 days in our bees kept in satiated conditions, which would mean a life-long infection for worker bees in the wild. However, our data show a significant variation between colonies in viral replication levels (across several orders of magnitude at day four and six post-infection) and their ability to clear infection, suggesting a genetic basis for defence that is likely to be reflected in wild bumblebees.

Over $20 \%$ of the control bees became infected with SBPV indirectly. While contamination via plastic-ware cannot be categorically ruled out, this raises the possibility that SBPV may be an airborne pathogen. In addition, Graystock et al. (2016) recently showed that commercial irradiated pollen can still contain pathogens, and although they did not test for SBPV this is a possibility.
It is noteworthy that there was no difference in survival of SBPV-infected bees, whether they were orally inoculated with a $5 \mu$ l dose or indirectly infected; it appears that SBPV is highly transmittable at low doses.

In summary, we have demonstrated that a common honeybee and bumblebee pathogen, that may appear asymptomatic in field collections and under optimal lab conditions, exerts a fitness cost on bumblebees under adverse conditions. Our results show the importance of examining subtle fitness effects when assessing a pathogen's effect on its host. Additionally, we found that larger bumblebees-indicating energy-rich conditions during larval growth - had a higher longevity and individuals that survived starvation conditions for longer had larger fat reserves. Providing good forage opportunities for pollinators may thus directly contribute to their longevity and resistance to stressful conditions. This highlights the importance of providing forage opportunities for pollinators throughout the season, as laid out, for example, in the UK's National Pollinator Strategy (DEFRA 2014). A wider uptake of conservation measures in land management under schemes such as the Countryside Stewardship in the UK could directly impact longevity and disease tolerance in pollinators.

Conditions in the lab are extremely favourable, e.g. individual lifespan under laboratory conditions exceeds the natural lifespan of worker bees in the field (SchmidHempel and Heeb 1991), such that laboratory studies can underestimate the impact of a pathogen. The use of sentinel species in studies of a multi-host-virus system may misrepresent the true impact of a pathogen on wild pollinator populations, as hosts can vary in their susceptibility to viruses (McMahon et al. 2015). In addition, estimates of virus prevalence are believed to be underestimated (McMahon et al. 2015). Thus, the impact of SBPV on natural populations may be greater than predicted. Indeed, it is possible that SBPV does affect longevity under satiated nutritional conditions in the wild, as workers would face additional ecological and environmental stressors such as inclement weather, energetically costly foraging and exposure to pesticides and pollutants. More broadly, this demonstrates that impact assessments of emerging multi-host pathogens, such as West Nile Virus in the USA (Kilpatrick 2011) need to take into account the pathogen's ecology rather than narrowly focusing on the most tractable laboratory model system.

Acknowledgements This work was funded by a Royal Society Dorothy Hodgkin fellowship to LW and a NERC studentship to RM. We would like to thank Jess Lewis and Katherine Roberts for help with the experiment, Devi Newcombe, Caroline Moussy, Corrina Lowry, John Hunt and Bryony Williams for assistance in the lab, Ken Haynes and group for the use of their lab and equipment, and Elze Hesse and James Cresswell for statistical advice. 
Author contribution statement RM and LW conceived and designed the experiments. RM performed the experiments. RM analysed the data with statistical advice from MB. RM and LW wrote the manuscript; MB provided editorial advice.

\section{Compliance with ethical standards}

Conflict of interest The authors declare that they have no conflict of interest.

Data accessibility If this paper is accepted for submission I intend to archive the original data using Dryad.

Open Access This article is distributed under the terms of the Creative Commons Attribution 4.0 International License (http://creativecommons.org/licenses/by/4.0/), which permits unrestricted use, distribution, and reproduction in any medium, provided you give appropriate credit to the original author(s) and the source, provide a link to the Creative Commons license, and indicate if changes were made.

\section{References}

Alaux C, Ducloz F, Crauser D, Le Conte Y (2010) Diet effects on honeybee immunocompetence. Biol Lett 6:562-565

Amdam GV, Omholt SW (2002) The regulatory anatomy of honeybee lifespan. J Theor Biol 216:209-228

Anderson RM, May RM (1981) The population dynamics of microparasites and their invertebrate hosts. Philos Trans R Soc Lond B 291:451-524

Bailey L, Woods RD (1974) Three previously undescribed viruses from the honey bee. J Gen Virol 25:175-186

Barrow DA, Pickard RS (1985) Larval temperature in brood clumps of Bombus pascuorum (Scop.). J Apic Res 24:69-75

Bates D, Maechler M, Bolker B, Walker S (2015) Fitting linear mixed-effects models using lme4. J Stat Softw 67:1-48. doi:10.18637/jss.v067.i01

Boots M, Begon M (1994) Resource limitation and the lethal and sublethal effects of a viral pathogen in the Indian meal moth, Plodia interpunctella. Ecol Entomol 19:319-326

Brown MJF, Loosli R, Schmid-Hempel P (2000) Condition-dependent expression of virulence in a trypanosome infecting bumblebees. Oikos 91:421-427

Brown MJF, Schmid-Hempel R, Schmid-Hempel P (2003) Strong context-dependent virulence in a host-parasite system: reconciling genetic evidence with theory. J Anim Ecol 72:994-1002

Carreck NL, Ball BV, Martin SJ (2010) Honey bee colony collapse and changes in viral prevalence associated with Varroa destructor. J Apic Res 49:93-94

Cartar RV, Dill LM (1991) Costs of energy shortfall for bumblebee colonies: predation, social parasitism, and brood development. Can Entomol 123:283-293

Cox-Foster DL (2007) A metagenomic survey of microbes in honey bee colony collapse disorder. Science 318:283-287

Cresswell JE et al (2012) Differential sensitivity of honey bees and bumble bees to a dietary insecticide (imidacloprid). Zoology 115:365-371

de Miranda JR et al (2010) Genetic characterization of Slow Bee Paralysis Virus of the honeybee (Apis mellifera L.). J Gen Virol 91:2524-2530

DEFRA (2014) National pollinator strategy: for bees and other pollinators in England, https://www.gov.uk/government/ publications/national-pollinator-strategy-for-bees-and-otherpollinators-in-england. Accessed 04 May 2015

Degrandi-Hoffman G, Chen Y, Huang MH (2010) The effect of diet on protein concentration, hypopharyngeal gland development and virus load in worker honey bees (Apis mellifera IL.). J Insect Physiol 56:1184-1191

Di Prisco G, Pennacchio F, Caprio E, Boncristiani HF Jr, Evans J, Chen Y (2011) Varroa destructor is an effective vector of Israeli acute paralysis virus is the honeybee, Apis mellifera. $\mathrm{J}$ Gen Virol 92:151-155

Di Prisco G et al (2013) Neonicotinoid clothianidin adversely affects insect immunity and promotes replication of a viral pathogen in honey bees. PNAS 110:18466-18471. doi:10.1073/pnas.1314923110

Doums C, Moret Y, Benelli E, Schmid-Hempel P (2002) Senescence of immune defence in Bombus workers. Ecol Entomol 27:138-144

Ellers J (1996) Fat and eggs: an alternative method to measure the trade-off between survival and reproduction in insect parasitoids. Neth J Zool 46:227-235

Evison SEF et al (2012) Pervasiveness of parasites in pollinators. PLoS One 7:e30641. doi:10.1371/journal.pone.0030641

Fürst MA, McMahon DP, Osborne JL, Paxton RJ, Brown MJF (2014) Disease associations between honeybees and bumblebees as a threat to wild pollinators. Nature 506:364-366. doi:10.1038/nature 12977

Garibaldi LA et al (2013) Wild pollinators enhance fruit set of crops regardless of honey bee abundance. Science 339:16081611. doi: $10.1126 /$ science. 1230200

Genersch E et al (2010) The German bee monitoring project: a long term study to understand periodically high winter losses of honey bee colonies. Apidologie 41:332-352. doi:10.1051/ apido/2010014

Gorbunov PS (1987) Endoparasitic flagellates of the genus Crithidia (Trypanosomatidae, Zoomastigophorea) from alimentary canal of bumblebees. Zoologicheskii Zhurnal 66:1775-1780

Gorbunov PS (1996) Peculiartities of life cycle in flagellate Crithidia bombi (Protozoa, Trypanosomatidae). Zoologicheskii Zhurnal 75:803-810

Goulson D, Nicholls E, Botías C, Rotheray EL (2015) Bee declines driven by combined stress from parasites, pesticides, and lack of flowers. Science 347:1255957

Graystock P, Yates K, Evison SEF, Darvill B, Goulson D, Hughes WOH (2013) The Trojan hives: pollinator pathogens, imported and distributed in bumblebee colonies. J Appl Ecol 50:1207-1215

Graystock P et al (2016) Hygienic food to reduce pathogen risk to bumblebees. J Invertebr Pathol 136:68-73. doi:10.1016/j. jip.2016.03.007

Hatcher MJ, Dick JTD, Dunn AM (2006) How parasites affect interactions between competitors and predators. Ecol Lett 9:1253-1271

Heinrich B (1974) Thermoregulation in bumblebees. 1. Brood incubation by Bombus vosnesenkii queens. J Comp Physiol 88:129-140

Horňáková D, Matoušková P, Kindl J, Valterová I, Pichová I (2010) Selection of reference genes for real-time polymerase chain reaction analysis in tissues from Bombus terrestris and Bombus lucorum of different ages. Anal Biochem 397:118-120

Jaenike J, Benway H, Stevens G (1995) Parasite-induced mortality in Mycophagous Drosophila. Ecology 76:383-391

Jensen C, Schaub GA, Molyneux DH (1990) The effect of Blastocrithdia triatomae (Trypanosomatidae) on the midgut of the reduviid bug Triatoma infestans. Parasitology 100:1-10

Jokela J, Taskinen J, Mutikainen P, Kopp K (2005) Virulence of parasites in hosts under environmental stress: experiments with anoxia and starvation. Oikos 108:156-164 
Kilpatrick AM (2011) Globalization, land use, and the invasion of West Nile virus. Science 334:323-327

Koch H, Schmid-Hempel P (2011) Socially transmitted gut microbiota protect bumble bees against an intestinal parasite. PNAS 108:19288-19292. doi:10.1073/pnas.1110474108

Koch H, Schmid-Hempel P (2012) Gut microbiota instead of host genotype drive the specificity in the interaction of a natural hostparasite system. Ecol Lett 15:1095-1103

Koella JC, Offenberg J (1999) Food availability and parasite infection influence the correlated responses of life history traits to selection for age at pupation in the mosquito Aedes aegypti. J Evol Biol 12:760-769

Leggett HC, Buckling A, Long GH, Boots M (2013) Generalism and the evolution of parasite virulence. Trends Ecol Evol 28:592-596

Levitt AL et al (2013) Cross-species transmission of honey bee viruses in associated arthropods. Virus Res 176:232-240

Manley R, Boots M, Wilfert L (2015) Emerging viral disease risk to pollinating insects: ecological, evolutionary and anthropogenic factors. J Appl Ecol 52:331-340

Martin SJ (2001) The role of Varroa and viral pathogens in the collapse of honeybee colonies: a modelling approach. J Appl Ecol 38:1082-1093

Martin SJ et al (2012) Global honey bee viral landscape altered by a parasitic mite. Science 336:1304-1306. doi:10.1126/ science. 1220941

McMahon DP, Fürst MA, Caspar J, Theodorou P, Brown MJF, Paxton RJ (2015) A sting in the spit: widespread cross-infection of multiple RNA viruses across wild and managed bees. J Anim Ecol 84:615-624

Meeus I, de Miranda JR, de Graaf DC, Wäckers F, Smagghe G (2014) Effect of oral infection with Kashmir bee virus and Israeli acute paralysis virus on bumblebee (Bombus terrestris) reproductive success. J Invertebr Pathol 121:64-69

Moret Y, Schmid-Hempel P (2000) Survival for immunity: the price of immune system activation for bumblebee workers. Science 290:1166-1167
Moret Y, Schmid-Hempel P (2009) Immune responses of bumblebee workers as a function of individual and colony age: senescence versus plastic adjustment of the immune function. Oikos 118:371-378

Nazzi F et al (2012) Synergistic parasite-pathogen interactions mediated by host immunity can drive the collapse of honeybee colonies. PLoS Pathog 8:e1002735. doi:10.1371/journal. ppat. 1002735

Restif O, Kaltz O (2006) Condition-dependent virulence in a horizontally and vertically transmitted bacterial parasite. Oikos 114:148-158

Santillán-Galicia MT, Ball BV, Clark SJ, Alderson PG (2014) Slow bee paralysis virus and its transmission in honey bee pupae by Varroa destructor. J Apic Res 53:146-154

Schmid-Hempel P, Heeb D (1991) Worker mortality and colony development in bumblebees, Bombus lucorum (L.) (Hymenoptera, Apidae). Mitt der Schweize entomologischen Ges 64:93-108

Singh R et al (2010) RNA viruses in hymenopteran pollinators: evidence of inter-taxa virus transmission via pollen and potential impact on non-Apis hymenopteran species. PLoS One 5:e14357. doi:10.1371/journal.pone.0014357

Steinhaus M (1958) Stress as a factor in insect disease. In: Proceedings of the 10th international conference of entomology 4, pp $725-730$

Therneau T (2008) Survival: survival analysis, including penalised likelihood, http://cran.r-project.org/web/packages/survival. Accessed 08 Aug 2015

Vanbergen AJ et al (2013) Threats to an ecosystem service: pressures on pollinators. Front Ecol Environ 11:251-259. doi:10.1890/120126

Yang X, Cox-Foster DL (2005) Impact of an ectoparasite on the immunity and pathology of an invertebrate: evidence for host immunosuppression and viral amplification. PNAS 102:7470-7475 